University of Washington Tacoma

UW Tacoma Digital Commons

Social Work \& Criminal Justice Publications

Social Work \& Criminal Justice

5-18-2016

\title{
Gender Transformative Approaches to Engaging Men in Gender-Based Violence Prevention: A Review and Conceptual Model
}

Erin Casey

University of Washington Tacoma, ercasey@uw.edu

Juliana Carlson

Sierra Two Bulls

Aurora Yager

Follow this and additional works at: https://digitalcommons.tacoma.uw.edu/socialwork_pub

Part of the Social Work Commons

\section{Recommended Citation}

Casey, Erin; Carlson, Juliana; Two Bulls, Sierra; and Yager, Aurora, "Gender Transformative Approaches to Engaging Men in GenderBased Violence Prevention: A Review and Conceptual Model" (2016). Social Work \& Criminal Justice Publications. 433.

https://digitalcommons.tacoma.uw.edu/socialwork_pub/433

This Article is brought to you for free and open access by the Social Work \& Criminal Justice at UW Tacoma Digital Commons. It has been accepted for inclusion in Social Work \& Criminal Justice Publications by an authorized administrator of UW Tacoma Digital Commons. 


\section{Gender transformative approaches to engaging men in gender-based violence prevention:}

\section{A review and conceptual model}

\section{Corresponding author:}

Erin Casey

University of Washington, Tacoma Social Work Program

1900 Commerce Box 358425

Tacoma, WA 98402

ercasey@uw.edu

253.692 .4524

Juliana Carlson

University of Kansas School of Social Welfare

Sierra Two Bulls, BA

University of Kansas School of Social Welfare Masters Program

Aurora Yager, BSW

School of Public Affairs and Administration at the University of Kansas

Acknowledgements: The authors would like to thank Tatiana Masters and Kelly Cue Davis for their thoughtful comments on an earlier version of this manuscript. 


\begin{abstract}
:
Engaging men and boys as participants and stakeholders in gender-based violence (GBV) prevention initiatives is an increasingly institutionalized component of global efforts to end GBV. Accordingly, evidence of the impact of men's engagement endeavors is beginning to emerge, particularly regarding interventions aimed at fostering gender equitable and non-violent attitudes and behaviors among men. This developing evidence base suggests that prevention programs with a "gender transformative" approach, or an explicit focus on questioning gender norms and expectations, show particular promise in achieving GBV prevention outcomes. Interventions targeting attitude and behavior change, however, represent just one kind of approach within a heterogeneous collection of prevention efforts around the globe, which can also include community mobilization, policy change, and social activism. The degree to which gender transformative principles inform this broader spectrum of men's engagement work is unclear. The goals of this paper are twofold. First, we offer a conceptual model that captures and organizes a broader array of men's anti-violence activities in three distinct but inter-related domains: 1) initial outreach and recruitment of previously unengaged males, 2) interventions intended to promote gender-equitable attitudes and behavior among men, and 3) gender equityrelated social action aimed at eradicating GBV, inclusive of all genders' contributions. Second, we review empirical literature in each of these domains. Across these two goals, we critically assess the degree to which gender transformative principles inform efforts within each domain, and we offer implications for the continuing conceptualization and assessment of efforts to increase men's participation in ending GBV.
\end{abstract}


Engaging men in violence prevention - 2

\section{Gender transformative approaches to engaging men in gender-based violence prevention: \\ A review and conceptual model}

Globally, the prevalence, intractability, and impact of intimate partner and sexual violence have generated the recognition that the prevention of gender-based violence (GBV) requires broad community participation, and particularly the participation of men and boys. Accordingly, the past two decades have witnessed a proliferation of programs and strategies designed to engage men and boys in violence prevention, either within the context of genderspecific (male-only) programming, or as a component of efforts to educate and mobilize communities as a whole. Over time, 'men's engagement' as an over-arching endeavor has grown to include and signal a broad range of activities. These encompass goals ranging from raising men's awareness about GBV, to fostering individual men's capacity to cultivate respectful and gender-equitable relationships in their families and social networks, to engaging men as social change agents with the skills to agitate for policy and social norm change consistent with safe and gender-equitable communities (Carlson et al., 2015).

Mounting global evidence suggests that men's engagement programming incorporating a 'gender transformative' approach is more likely to successfully shift men's gender and violencerelated attitudes and behaviors than programs which do not explicitly address ideas about gender norms (Barker, Ricardo \& Nascimento, 2007). Gender transformative approaches are more fully described and conceptualized below, but in brief, programs can be categorized as gender transformative if they explicitly focus at least in part on a critical examination of gender-related norms and expectations (particularly those related to masculinity), and on increasing genderequitable attitudes and behaviors (Barker et al., 2007; Gupta, 2000). 
The over-arching purpose of this review is to apply a gender transformative lens to summarizing current literature regarding effective strategies for promoting men's anti-GBV engagement. While the heterogeneous range of approaches, programs, and movements globally have often been treated as a somewhat unified "men's engagement" construct within GBV prevention discourse, we argue for the conceptual utility of viewing men's anti-violence involvement as a set of more specific categories. To this end, we first offer a conceptual model that disaggregates men's anti-violence engagement activities into three domains organized both temporally and by the goals of the work within those categories. These include 1) initial outreach to and recruitment of previously unengaged men, 2) interventions aimed at shifting men's attitudes and behaviors, and 3) social action aimed at eradicating GBV. We next define a gender transformative lens and summarize the rationale for engaging men through this perspective. Finally, we offer reviews of available literature regarding promising and effective gender transformative strategies for our first two proposed domains; initial outreach, and interventions aimed at attitudinal and behavioral change. Our greater focus on reviewing literature pertinent to the first two domains reflects, in part, the relative greater availability of peer reviewed literature in these areas. We conclude with a brief commentary on emerging literature regarding the conceptualization of the third domain, social action, and on the relationship of the first two domains to the integration of men into this activist, over-arching goal of ending GBV.

In summarizing the knowledge base regarding engaging men and boys in prevention through a gender transformative lens, our aim is not to elevate men's participation as an end unto itself. Instead, we join Jewkes et al. (2015) in arguing for the importance of males in violence prevention as one integral component of comprehensive efforts to end violence globally and ultimately, to promote gender justice. Because gender ideologies are embedded in both male- 
identified individuals' risk for perpetrating violence, and their willingness to participate in preventing it, however, the project of engaging men requires careful thinking about how to appeal to men without reinforcing notions of gender hierarchy. This tension necessitates evaluating and surfacing the role of gender in men's anti-GBV involvement. Additionally, in focusing on "engaging men" through gender transformative approaches, we recognize that we run the risk of reifying notions of a gender binary and gender as embodied; indeed this is a critique of gender transformative approaches more generally (see for review, Dworkin, Flemming \& Colvin, 2015). At the same time, given the centrality of gender ideologies and associated power inequities to violence risk and prevention, we suggest that violence prevention approaches which do not explicitly evoke participants' ideas about their own gender identities and gender norms elide a fundamental contributor to intractable interpersonal violence. Critically assessing widely-held notions of appropriate ways of "doing gender" indeed sit at the heart of conceptualizing gender transformative programming, and may also ultimately contribute to emancipatory gains related to gender identities. For the purposes of parsimony in the remainder of the paper, we will use the term "men's engagement," terminology representing work with all male-identified individuals, inclusive of both men and boys.

\section{Men's anti-violence engagement: A conceptual model}

As noted above, efforts to increase men's anti-violence involvement are myriad, and include, but are not limited to, one-time community events, standardized interventions aimed at violence-related attitude and behavior change, as well as a range of community outreach, education, mobilization, and social action efforts (Carlson et al., 2015). In addition to their heterogeneity, activities under the umbrella of "men's engagement” encompass a temporal dimension. Prior to entering formal education programs or interventions, men must first seek 
involvement, or be located, "engaged," and invited into participation. This front end stage is often not explicitly conceptualized or addressed in the evaluation of GBV prevention programs. On the back end, many programs that engage men and boys also have aspirations to foster men's identities as change agents and to leverage their participation in on-going community and social action (sometimes outside the context of a formal intervention program). This activism, in turn, may create pathways for still more men to be engaged as activist men become visible in their social networks and communities. To date, however, clear conceptual distinctions between these types and phases of men's GBV prevention participation have not been consistently articulated.

Figure 1 depicts a proposed conceptual model, inclusive of the three aforementioned domains shown in a reciprocally influential cycle. Here, initial recruitment of men and boys provides a conduit to formalized prevention events and interventions, which, in turn hold promise for fostering activism and integration into larger GBV prevention efforts and, more broadly, gender justice movements. Subsequent activism (in addition to potentially addressing structural factors that support gender GBV) can generate new spaces in which initial outreach to previously unengaged men may occur. We offer this model as a way to consider the unique dimensions of these domains as well as the possibility that particular strategies and messaging will be differentially effective at supporting men's antiviolence involvement within each category. At the same time, we hope to retain the notion tailoring anti-violence engagement for male-identified individuals is just one component of a comprehensive, gender-inclusive campaign to eradicate GBV. Using this model as a starting point, we also critically evaluate the ways that gender transformative principles have informed efforts within each domain. 
The rationale for a focus on men's engagement as a component of the broader goal of GBV prevention has been widely articulated elsewhere (e.g. most recently, Jewkes, Flood \& Lang, 2015; Peacock \& Barker, 2014), and encompasses a gendered analysis of violence. In brief, globally, the majority of intimate partner and sexual violence resulting in serious injury or other psychological or economic consequences is perpetrated by men (Black et al., 2011; see for review, Jewkes et al., 2015). Furthermore, men's use of violence in their heterosexual relationships is consistently associated with adherence to traditional notions of masculinity that emphasize dominance over and hostility toward women (see for review, Flood \& Pease, 2009). For this reason, we employ the term "gender-based violence" in this review to refer to intimate partner and sexual violence. These empirically supported notions that particular, traditional conceptualizations of masculinity create risk for men's violence and explain, in part, the gender disparity in perpetration constitute a direct corollary to the emergence of "gender transformative" conceptualizations of prevention. The term gender transformative is predominantly used to identify programmatic efforts to end GBV and HIV-social problems with gender relations at the core. Over that last fifteen years organizations such as the United Nations Population Fund, Promundo, Sonke, as well as HIV-specific organizations, like UNAIDS, have adopted the term gender transformative to describe programs seeking to increase gender equity, and to inspire governments, organizations, and individuals engaged in this work to embrace this framework (e.g. Kaufman et al., 2014).

Gita Rao Gupta is credited with the origins of the term gender transformative, stemming from her 2000 lecture where she delineated a continuum of specific categories of approaches to the efforts to address gender, sexuality, and HIV. Within this continuum, Gupta (2000) outlined five categories of interventions: reinforcing damaging gender and sexuality stereotypes, gender 
neutral, gender sensitive, gender transformative, and gender empowering. These are delineated on a continuum of "progress," implying that the gender transformative end of the valence is more desirable and supportive of social change. Although a full explication of the spectrum is beyond the scope of this review, in brief, Gupta posits that only gender transformative and gender empowering approaches address the actual gendered social inequity that underlies GBV and the sexual and economic marginalization of women. The goals of gender transformative and empowering programs are to foster gender-equitable attitudes, behaviors, and community structures that support both men and women in full community participation and (in the case of gender empowering strategies), "to free women and men from the impact of destructive gender and sexual norms" (Gupta, 2000, p. 11).

In 2010, the United Nations Population Fund (UNFPA) and Promundo, two leaders in funding and implementing GBV prevention programming, adapted Gupta’s conceptualization into a four category gender programming continuum: gender exploitative, gender neutral, gender sensitive, and gender transformative. Given the relative rarity of programs that meet a truly "gender empowering" standard (Gupta, 2000), the gender transformative approach has emerged as the current ideal for prevention interventions. This is a prevalent approach particularly in low to middle income countries, in which prevention initiatives often holistically target multiple gender-related outcomes, including GBV, family, sexual, and reproductive health, access to education, and/or economic well-being (Dworkin et al., 2013). More recent operationalization of what constitutes a gender transformative approach reflects this broader lens; the UNFPA and Promondo (2010) state that gender transformative programs "seek to transform gender relations through critical reflection and the questioning of individual attitudes, institutional practices and broader social norms that create and reinforce gender inequalities and vulnerabilities" (p. 14). 
The main rationale for prioritizing gender transformative prevention interventions is the global evidence demonstrating that programs using this approach are effective at supporting attitude and behavior change among men, as demonstrated by three recent and large-scale reviews (Barker et al., 2007; UNFPA \& Promondo, 2010; Dworkin, et al., 2013). The 2007 World Health Organization Report authored by Barker and colleagues also concludes that programs with a gender transformative component outperform those that are gender neutral or gender sensitive. Further, given that empirical studies show an associative relationship between masculine gender role ideologies and sexual risk (i.e. unprotected vaginal sex) as well as intimate partner violence in young men's heterosexual relationships (Santana, Raj, Decker, La Marche, \& Silverman, 2006), addressing gender norms within prevention interventions can have impact across multiple health, sexual, and safety-related outcomes. Scholars and preventionists increasingly argue that acknowledging and addressing gender norms is therefore central to change work with men (Jewkes et al., 2015). On a broader horizon, holding up the gender transformative approach as the gold standard of GBV prevention interventions lays groundwork for increasing the number of "gender empowering" approaches to moving toward gender equity (Gupta, 2000).

\section{Domain 1: Initial outreach to men: Conceptualizing a gender transformative approach}

Most of the literature on gender transformative approaches to GBV prevention focus on the outcomes of distinct, standardized programs that are implemented in communities over time. Initiating these programs, however, requires the recruitment of participants, and sparking an initial willingness among men to be exposed to prevention events or programming. This early outreach and invitation stage of men's engagement is less well conceptualized in existing literature, is often not described in detail in the context of intervention evaluations, and is rarely 
addressed explicitly through a gender transformative lens. As noted above, we argue for conceptually disaggregating the assessment of outreach efforts from the assessment of formal interventions for the purpose of understanding the unique considerations involved in convincing male-identified individuals that an issue they may not have previously attended to is worth their time and attention. The nature of initial outreach may shape men's expectations for what participation in prevention programs will be like, systematically attract or exclude certain groups of men, and influence differential success or attrition in programs.

Additionally, evidence suggests that notions of gender and the principles of gender transformative work are highly relevant to this stage of men's engagement. On a very fundamental level, male gender identity may inhibit the extent to which discussions of violence are perceived by men as even tangentially relevant to their lives; in a study by Rich et al. (2010), for example, over $50 \%$ of college-age men in a U.S. sample stated that they would not support or attend a voluntary education opportunity regarding sexual assault prevention because it did not apply to them specifically as men, or as people who were not, themselves, engaged in violent behavior. Adherence to traditional ideas about masculinity may further exacerbate this disconnect. Endorsing traditional masculinity is not only associated with risk for violence perpetration, as noted above, but is also correlated to a lack of confidence in taking actions that could interrupt or prevent violence among men in the U.S. (Allen, 2010). Even men who do not personally endorse traditional ideas about masculinity are impeded by those ideas from taking anti-violence actions. Men report that the notion of intervening in another male's disrespectful or abusive behavior toward a woman is hindered by fears of being labeled weak or 'wimps' by male peers (e.g. McMahon \& Dick, 2011). Taken together, these emerging findings suggest that men's 
ideas about gender are part of the complex calculus involved in the extent to which GBV prevention efforts or actions feel relevant, important, or accessible to men.

The remainder of this section summarizes the current evidence base regarding promising strategies for reaching out to men to invite their initial participation in GBV prevention activity. Additionally, we assess the degree to which gender transformative approaches are embedded in existing strategies for initiating men's engagement. Research articles informing this section were located through searches of the PsychInfo, PubMed, Web of Science, and Google Scholar databases using the terms "“engaging men," "involving men," "outreach to men" or "men and allies," coupled with the terms "violence" and "prevention." Forward and backward citation searches on included articles were also conducted. Inclusion criteria were that articles were available in English and described findings related to strategies for inviting men's anti-violence participation or to men's perceptions of effective strategies for engaging others. Articles that addressed men's attitudes toward GBV in general, but did not link these attitudes to factors associated with men's engagement in prevention were excluded, as were empirical outcome evaluations of more comprehensive violence prevention programs. These are included in the next section on reviewing evidence related to attitude and behavior change.

In total, 12 peer-reviewed articles and one book were located using these criteria; these are flagged with stars in the reference section. All of the identified sources were descriptive and most were qualitative; articles largely retrospectively explored engaged men's reasons for getting involved in anti-violence work and/or their perceptions of effective approaches to initially reaching out to other men. We did not locate any quantitative evaluations of the relative effectiveness of various outreach strategies - thus, what follows is a summary of descriptive and emerging evidence of promising, though formally untested outreach strategies. Further, 
somewhat surprisingly, none of the studies invoked an exclusively gender transformative conceptualization of initial outreach strategies. Because of this, we elected to include articles on initial engagement that were consistent with the above inclusion criteria even though they did not explicitly employ a gender transformative analysis. In our analysis of this domain, therefore, we identify areas of overlap and disconnect between the emerging literature on men's initial engagement and a gender transformative lens, and conclude this section with comments regarding implications for conceptualizing gender transformative outreach to male-identified individuals. For parsimony, we organized the recurring elements of initial violence prevention outreach to male-identified individuals in five domains. These were developed by the first author via a listing of all factors associated with men's initial engagement across studies, and a thematic analysis of those factors into larger conceptual categories.

\section{Recruitment through social networks: The role of credible messengers and role}

models. Across studies and geographic regions, the perceived effectiveness of leveraging men's social networks and community affiliations in outreach efforts consistently emerged. Concretely, recruiting through connection tended to be described in two ways: 1) reaching men through their existing individual relationships, and 2) mobilizing community-specific ambassadors or role models. In studies of male anti-violence allies discussing their own entrée into violence preventative work, many of the men in North American samples (Alcalde, 2014; Casey \& Smith, 2010; Coulter, 2008; Piccigallo, Lilley \& Miller, 2012) noted that they initially found their way to prevention events through being encouraged by someone they knew and respected. For example, in a qualitative study of 10 Canadian adolescent boys who reported some level of involvement in gender equity work, some of the young men identified their respected male peers' involvement or encouragement from feminist mentors as catalysts (Coulter, 2008). 
Similarly, in the sole quantitative article located for this review, Casey et al. (2016) describe findings from a global survey of 392 men who had recently attended a violence prevention event or become involved in GBV prevention work. Over half of men in this sample reported being encouraged to initiate involvement by someone close to them. These findings are echoed in discussions of male allies' perceptions of what best attract other men to GBV prevention work. Carlson and colleagues (2015) conducted interviews with 29 representatives of anti-violence organizations globally and elicited perceptions of effective recruitment and engagement strategies. Nearly half of the representatives reported that individualized invitations to men are a strategy they employ, often accompanied by a concrete action men can take such as signing a pledge or helping at an event. Similarly, in a qualitative study of 27 anti-violence male allies in the US, nearly two thirds of participants reported leveraging their own social networks and relationships to recruit participation by other men, and to tailor their appeals to individual men they know personally (Casey, 2010).

Other studies suggest that social networks are best leveraged by recruiting members of specific communities or constituencies, and training and supporting them to be "ambassadors" of GBV prevention in their own contexts. This was a strategy endorsed by several of the antiviolence organizations around the world interviewed by Carlson et al. (2015), who articulated the notion that community members are best positioned to be credible GBV prevention messengers who can tailor their approaches in culturally specific ways. Similarly, a sample of U.S. men who recently attended GBV prevention and ally-building presentations felt that enlisting members of communities or groups such as fraternities to "infiltrate" and engage other men was a promising way to successfully enlist more men's participation (McMahon \& Dick, 2011). Finally, in an evaluation of an HIV and violence prevention program for men in South Africa, Kalichman and 
colleagues (2008) found that a respondent-driven sampling approach (in which initial program participants approach and recruit future program participants) was an effective way to recruit and to diffuse program effects into social networks. Taken together, these findings suggest the utility of outreach approaches that reach men one at a time in tailored ways, through existing social relationships and by individuals who are trusted, credible members of local communities.

\section{Recruitment through context: Culturally and community-specific strategies.}

Dovetailing with the notion of engagement through existing social connections is the clear mandate to situate outreach and prevention efforts within the norms, culture, structures, and history of men's communities. Across the literature, this has been operationalized as supporting community mobilization from within natural community leadership structures (e.g. Carlson et al., 2015), and as formative, qualitative work with men who are members of "target" communities prior to the initiation of outreach. Formative work allows for the elicitation of beliefs about issues of gender, insuring the incorporation of local expertise into the design of engagement strategies and culturally relevant messaging. For example, in a study of South African men's beliefs about gender equality, Dworkin and colleagues (2012) argue that gender equity-related outreach to men must first surface and incorporate men's locally specific beliefs and experiences around gender and masculinity, and include their voices in the design of recruitment, messaging, and programming. In one example of a community-specific approach to engagement, men and women in several post-conflict communities across five African and Asian countries were invited to participate in creating videos documenting gender-related issues of concern to their communities (Gurman et al., 2014). Resulting videos were therefore highly relevant to the many small communities from which they emerged, and were effective avenues for generating conversation about sensitive issues among other community members who viewed 
the videos at "playback" sessions. Organizational representatives in the Carlson et al. study (2015) also endorsed "embedding engagement strategies in naturally occurring and culturally compelling forms of discourse," (p. 12) such as community-specific arts and cultural events or historically familiar forms of activism such as protest marches.

Recruitment through a personal, emotional connection. Next, several studies (primarily from North America) described the importance of helping men to make an emotional connection to the reality and impact of violence. Concretely, fostering a personal connection to violence was operationalized in a variety of ways. For example, in their qualitative study of precipitates to involvement for male anti-violence allies, Casey \& Smith (2010) found that a variety of "sensitizing experiences," or opportunities to make emotional connections to issues of violence, were catalysts for joining anti-violence work for most men in the study. These experiences variably consisted of witnessing victimization in their own families or hearing disclosures of abuse from loved ones, thereby centering the reality and relevance of violence to their own lives. Other sensitizing experiences included hearing moving stories from survivors of violence or linking personal experiences of class, race, or sexuality-based marginalization to the oppression embedded in GBV. Similarly, Coulter (2008) and Alcalde (2014) found that opportunities to connect the topic of GBV to personal experiences of being judged or marginalized, experiencing victimization, and/or learning of the abuse experienced by loved ones as among the factors motivating anti-violence engagement in samples of Canadian youth and Latino men in the U.S., respectively. These findings were also echoed in a qualitative study of 25 U.S. college-age men engaged in anti-violence work, who cited disclosures of abuse from female friends and exposure to stories of violence against women on their campus as catalysts for involvement (Piccigallo et al., 2012). In a global, quantitative sample of men involved in GBV 
prevention, $59 \%$ of participants noted that their involvement was motivated at least in part by hearing a moving story about violence, $55 \%$ by hearing a disclosure from a loved one, and $27 \%$ because of being targeted for violence because of some aspect of their identity (Casey et al., 2016). Across studies, the practical implications of "sensitizing experiences" as an entrée to GBV prevention include providing men with concrete opportunities to be exposed to survivor stories, as well as offering men opportunities (such as through discussion groups) to make conceptual linkages between their own personal experiences of vulnerability and marginalization, and the impact of GBV on themselves and their community.

In particular, the relationship between men's multiple and intersectional identities, men's own experiences of marginalization, and relevant GBV prevention recruitment strategies is an emerging and important line of inquiry. In their review of global principles for men's anti-GBV engagement, Peacock and Barker (2014) highlight the importance of ensuring that efforts are “inclusive of and responsive to diversities among men" (p. 582). Emerging evidence also documents the ways that intersectionality has been part of the pathway to many men's engagement and is a vital aspect of conceptualizing inclusive engagement strategies. For example, in a 2014 qualitative study of Latino men in the U.S. who had attended violence-related prevention events and committed to a "non-violent masculinity," Alcalde (2014) found that men's experiences of marginalization based on race, immigration, and sexual identity sharpened their analysis of violence as connected to gender inequity and particular, "hegemonic" notions of masculinity. These connections were further facilitated through a discussion group for the men that allowed a safe space for reflection and connection (Alcalde, 2014). Similarly, several of the anti-violence allies in the U.S. interviewed by Messner, Greenberg, and Peretz (2015) noted that part of their pathway into anti-violence work included an understanding of structural 
vulnerability generated by experiencing or witnessing marginalization based on class, race and sexual identity. The notion of engagement through a mindfulness of intersectionality also comes the closest to an explicitly gender transformative recruitment approach among the strategies summarized here (through its analysis of identity, structural disadvantage, and privilege), further rendering it an important one to continue to concretely conceptualize and tailor across contexts.

Recruitment through hopefulness: A positive approach to men. Findings from several studies emphasized the importance of initial engagement efforts that approach men in a positive manner rather than as potential perpetrators. A positive approach that highlights men's roles and responsibilities to contributing to ending violence has long been held up as a general principle of outreach to men (e.g. Katz, 1995) and more recent studies of anti-violence male allies reinforce that this positive stance was central to their own and other men's successful engagement. Across studies, this was operationalized in similar ways, including communicating to men that they are part of the solution to ending violence (Piccigallo et al., 2012), have specific skills that are needed in the work (Casey \& Smith, 2010), and as maintaining an openly "hopeful" stance about men that assumes their willingness to act on the best behalf of their families and communities (Carlson et al., 2015). For example, in a 2010 study of a Frierian-informed, anti-violence discussion group with migrant farm workers in the U.S., Nelson and colleagues (2010) built their intervention design on findings from a formative survey with potential participants. Those findings suggested the importance of approaching men as loving, caring individuals who want to help stop violence against people they love, and of explicitly communicating an understanding of men's violence as something learned rather than inherent.

\section{Recruitment through "hooks:” Starting with relevant conversations. Finally,} tailoring initial conversations with men to the concerns most relevant and compelling to them 
was a strategy identified in three sources. In their global study of anti-violence organizational representatives, Carlson et al. (2015) note that several organizations reported focusing some of their early conversations with men not explicitly on violence but on topics related to men's concerns about fatherhood, sexual health, experiences of power and powerlessness, etc. Another example comes from an evaluation of an intervention aimed at reducing GBV in Cote-D'Ivoire (Falb et al., 2014). Men who completed the gender-related dialogue groups in this intervention reported that they were initially convinced to participate in part because the program promised to address issues of concern to them, including financial management and improving family relationships. Similarly, Nicaraguan men involved in a range of NGO-sponsored sexual health and violence prevention efforts reported that, among other reasons, the programs' efforts to provide sexual and reproductive health information deepened their interest in participating and staying involved (Torres, Goicolea, Edin, \& Öhman, 2012). Male allies in the U.S. also report that they consciously assess issues of importance and then tailor initial conversations with other potential GBV prevention allies on an individual basis, or use "broader conversations" about compelling topics like sex and relationships to pull men into discussion groups that will eventually address GBV (Casey, 2010). Strategically tailoring the focus of initial conversations is an approach that is also clearly linked to the notions of recruitment through context and personal connection described above, as both the topics of concern to men and the best ways of tackling them are linked to men's experiences and social location within their geographic and cultural contexts.

Summary and discussion of men's initial engagement. In summary, five inter-related categories emerged across the existing (and almost exclusively qualitative) literature regarding promising strategies for initial outreach to men. Running through these themes was the notion of 
tailoring and personal connection. Participants in the included studies were themselves engaged, or engaged others, largely through existing relationships or social networks, in locally and culturally compelling ways, with positive messages from relatable messengers, and through various means of connecting personally or emotionally with the topic of GBV. Further, although the above themes were summarized sequentially, evidence suggests that many of the men included in the studies had multiple influences on and motivations for their anti-violence engagement over time (e.g. Casey \& Smith; 2010; Messner et al., 2015). This suggests the importance of multiple, overlapping, and perhaps sequenced outreach and engagement strategies that build on sensitizing experiences or pre-existing points of connection for men.

Given the small number of available studies, more work is clearly needed to both conceptualize and evaluate this initial stage of men's engagement. Comparative evaluation of the efficacy and impact of different outreach and engagement strategies is also needed. It remains unclear, for example, whether particular strategies (or combinations of strategies) for encouraging men's attendance at GBV prevention events or programs like those described in the next section are more effective at actually triggering that attendance and at supporting sustained anti-violence participation over time. It may also be that some strategies are more successful than others at triggering an activist trajectory, versus one-time only participation in discrete prevention events. Finally, it is unclear whether these kinds of outreach strategies elicit more successful engagement than simply mandating men's presence at events, which is a strategy available in some contexts such as college campuses, workplaces, or military settings.

Across reviewed studies, factors associated with men's recruitment were largely not explicitly conceptualized through a gender transformative lens. Implicated in this gap is perhaps a fundamental paradox in the initial engagement of men in gender justice work. Successfully 
getting men into the door of GBV prevention events (outside of mandating their presence), requires reaching out in inviting, positive ways that minimize potential barriers, including those created by defensiveness (Casey, 2010). Starting with overt invitations to unpack notions of masculinity may run counter to this, and land on men as off-putting, although this assumption has not, to our knowledge, been formally tested. However, strategies that explicitly evoke gender by attempting to appeal to men "as men," in ways that leverage traditional masculinity (and which are not, therefore, "gender transformative"), risk reinforcing elements of gender hierarchy that GBV prevention efforts ultimately aim to unseat. An example of this can be seen in a recently published critique of campaigns such as the U.S.--based "Man Up Monday" materials, which Fleming, Lee, and Dworkin (2014) argue may have inadvertently done harm by promoting and reinforcing gender stereotypes (in this case, that men should have a lot of sexual partners) to motivate men to get tested for sexually transmitted diseases. Similarly, Jewkes et al. (2015) and Masters (2010) call into question outreach or advertising strategies that leverage hegemonic notions of male dominance in order to appeal to men, such as casting male anti-violence allies as “warriors," or as "real men." Hints of traditional masculinity may seep into engagement strategies in more subtle ways as well. For example, although exposing men to stories of (often female) survivors has been identified by many male allies as a personally important "sensitizing experience," this strategy also runs some risk of evoking paternalistic notions that men need to protect women from harm. And, as Piccigallo et al., (2012) note, overly depending on this creates a risk of burdening survivors, again usually women, to be responsible for and to trigger the anti-violence participation of men. While sharing stories can be a source of empowerment and healing for survivors, we worry that in the context of men's engagement efforts, relying unduly on survivors to help men make an emotional connection to the issue of GBV carries 
problematic parallels to the degree to which women are charged with preventing their own victimization more generally.

The accumulating evidence of the effectiveness of gender transformative interventions aimed at attitude and behavioral change among men (evidenced by findings in the next section) support the potential importance of more clearly operationalizing a gender transformative lens for initial outreach and recruitment strategies, and/or of more explicitly describing the ways in which some current outreach efforts already embody gender transformative traits. The relative youth of the literature base on initial outreach to men and boys, as well as the tendency to aggregate recruitment and intervention phases in conceptualizing GBV prevention programming may also, in part, explain the lack of initial engagement literature explicitly employing a gender transformative analysis.

Adding this lens may be a matter of, as Dworkin et al. (2012) argue, crafting messaging that is simultaneously informed by men's locally and culturally specific experiences of masculinity, but avoids appealing to the stereotypical or "hegemonic" masculine ideals associated with risk for violence. Drawing from the principles summarized above, this is perhaps best done by ambassadors and respected members of men's social networks who can explicitly model gender equitable attitudes and behaviors. This allows for gender-equitable socialization in culturally and contextually-specific ways, and in a tailored manner that makes space for potential ambivalence among new male "recruits." Gender transformative recruitment may also evoke and leverage men's pre-existing "sensitizing experiences" in ways that help them connect identity-based marginalization or victimization to structural oppression - including the oppression of women. For example, arguing that men possess the potential to achieve an "antipatriarchal gender consciousness" (pg. 514), Ratele (2014) suggests engaging men through a 
commitment to societal benefits of equality (as opposed to purely personal benefits) in ways that acknowledge some men's structural disadvantage and ambivalence about gender equity. This is also consistent with the principle of engaging men through optimism about their potential to be

full, willing contributors to social equality by eradicating gender violence. It is important to note that many organizations' efforts to recruit men likely incorporate these kinds of principles and that more work is needed to document and highlight the ways that initial engagement has already been conceptualized in gender transformative terms. Research testing the effectiveness of gender transformative initial engagement strategies is also needed to further develop and support outreach that is consistent with a gender transformative conceptualization.

\section{Review 2: Interventions to Shift Men's Attitudes and Behaviors}

Our second domain, interventions aimed at promoting gender-equitable attitudes and behaviors among men, is a more developed and evaluated field of inquiry. Still, the number of evaluation studies documenting the effectiveness of these interventions is fairly small, reflecting among other factors, the relative newness of efforts to engage men. As described previously, several key voices in the field promote the use of a gender transformative approach in the development and implementation of prevention interventions to engage men (Barker et al., 2007; Dworkin et al., 2013; Peacock \& Barker, 2014), and it is this subset of gender transformative interventions that we review here. The recent systematic review by Dworkin and colleagues (2013) of gender transformative HIV and violence prevention interventions with heterosexual men finds evidence of their effectiveness in changing attitudes and behaviors such as reported use of violence, gender norms, increase in care or domestic work, and social acceptance of IPV. The following review builds on Dworkin and colleagues' work, but narrows the scope to include only inventions with gender-based violence outcomes. Also, in order to provide a review of new 
evidence, this review excluded manuscripts included in Dworkin et al.'s 2013 review. Eight of the 10 studies in this review were therefore published since 2013. It should be noted that among these are three more recently published studies of programs that were reflected in the Dworkin et al. review; these newer studies were included because they reported findings for GBV-related outcomes that were not available in the 2013 review.

Inclusion criteria. Our search sought to locate studies of interventions with men to end gender-based violence using a gender transformative approach that documented attitudinal and behavior change using an experimental or a quasi-experimental design. Studies were identified using the following databases: PubMed, Proquest, Web of Science, and Google Scholar. Search terms and phrases included gender, men, gender-based, sexual, violence, prevention, intervention, prevention intervention, trial, program, and randomized trial. The inclusion criteria for this review were 1) the program or intervention must be gender transformative - as defined by Gupta as critically examining gender norms, 2) the evaluation of the program needed to assess at least one attitudinal or behavioral change in men related to a(n): increase in gender-equitable attitudes, decrease in reported IPV perpetration, increase in care or domestic work, and decrease in social acceptance of IPV, and 3) the article had to describe a quantitative and at least quasiexperimental evaluation of the program. Determining whether an intervention used a gender transformative approach was not a simple process as studies did not always categorize interventions in these terms. Instead, we used a multi-reviewer process to determine whether, based on the publication's description of intervention components, the program included explicit attention to addressing gender norms, as well as the other two eligibility criteria. Using the search terms identified above the review team conducted a wide search to identify "promising" articles, a classification that was met if the article appeared to meet at least one inclusion criteria 
based on the abstract. One person from the review team closely reviewed the promising articles to determine if the article met all three of the inclusion criteria, with particular attention to the gender transformative criteria. The lead reviewer (i.e. second author) reviewed articles determined by the first reviewer to meet all three criteria. The articles confirmed as meeting all criteria by the two reviewers were included in the final analysis.

\section{Results}

Of the 7,016 total articles looked at in the search process, 6,794 were removed after reviewing the abstracts. The 222 promising articles were reviewed. Of these, ten studies met all three inclusion criteria. Table 2 outlines the intervention components including the participants, geographic location, intervention approach and components, and summary of the four outcomes reviewed.

Interventions and contexts. Eight unique interventions were assessed across the ten identified studies; two studies were based on separate implementations of the SASA! intervention (Abramsky et al., 2014; Kyegombe et al., 2014), and two on tests of the Stepping Stones curriculum (coupled with different supplementary interventions) in different regions (Jewkes et al., 2014; Krishnan et al., 2012). The interventions took place in a variety of countries; with the majority of interventions being implemented in Africa; six of the eight unique interventions took place in African countries: Cote d'Ivoire (1), Ethiopia (1), Uganda (2), and South Africa (2). The global nature of these interventions mirrors Dworkin and colleagues' review (2013), where five took place in Africa, five in the US, three in Asia, and two in Latin America. The contexts of the different interventions in this review varied widely including: informal settlements (South Africa, Jewkes et al. 2014), conflict areas (Cote d'Ivoire; Hossain et al. 2014), heavily populated city centers (Addis Ababa, Ethiopia, Pulerwitz et al., 2015; Mumbai, 
India, Miller et al, 2014; Kampala, Uganda, Abramsky et al., 2014 and Kyegombe et al., 2014), and online with college students (USA, Salazar et al., 2014). The target population for most interventions was young men with the complete age bracket being 15 to 49 years. All interventions included in this review reflect a universal prevention approach; participants in the programs were community members and were recruited irrespective of past use of or risk for violence. Although the focus for this review was interventions to engage men and boys to prevent gender-based violence, five of the interventions also aimed to impact outcomes related to co-occurring risk factors, such as HIV (Abramsky et al., 2014; Jewkes et al., 2014; Kalichman et al., 2009; Kyegombe et al. 2014; Wagman et al., 2015) and sexually transmitted infections generally (Krishnan et al., 2012).

Gender transformative and interventive components. The operationalization of a gender transformative approach - critically examining gender norms -consistently contained language of promoting gender "equality" or "equity" across interventions. In this section, we briefly summarize each program in terms of its operationalization of "gender transformative approach" and the concrete interventive components used to deliver the gender transformative content. Three of these programs used a community mobilization approach, either alone or in combination with other intervention components. First, SASA! (Start, Awareness, Support, Action!; Abramsky et al., 2014; Kyegombe et al., 2014), used extensive community mobilizing implemented by locally engaged community activists who initiated discussion and advocacy within their social networks and through media. The phased intervention focused on initiating conversations about power, which were then leveraged to critically and explicitly examine relationship and sexual power inequities between genders. Similarly, The Male Norms Initiative (Pulerwitz et al., 2015), used community engagement activities such as marches, public theater, 
media and other events in combination with 8-session small group education activities for adolescent and young men. Based on the Theory of Gender and Power, interventive content focused on gender-related power inequities, gender norms, and the related outcomes of IPV and STIs. Finally, The Safe Homes and Respect for Everyone Project (Wagman et al., 2015), used community mobilization as a primary platform (inclusive of sponsoring community events, deploying trained community ambassadors, and engaging local community institutions) in combination with one-on-one HIV brief interventions and opportunities for the implementation of small group curricula for both young men exclusively and mixed-sex groups of young people. Based on Public Health and Stages of Change approaches, interventive content focused on risk factors for IPV and HIV, including gender norms and gender-related power inequities.

The remaining five programs used small group discussion and/or one-on one delivery formats. The Men and Women in Partnership Initiative (Hossain et al., 2014) implemented 16week discussion groups for men, and explicitly invoked the term "gender transformative" to define its approach. The discussion group curriculum was based in social norms theory, and fostered discussion about men's notions of gender and gender inequality, and supported participants in skill building related to conflict resolution and household labor negotiation. Although the program did not explicitly use a community mobilization approach, it did embed the discussion groups within "community-level programming" consisting of violence awarenessraising efforts. Next, the Stepping Stones program was implemented and evaluated in two sites; one in combination with the Creating Futures program (an economic and employment empowerment curriculum; Jewkes et al., 2014) and one in combination with one-on-one brief intervention and HIV testing (Krishnan et al., 2012). The Stepping Stones program involves parallel single-sex, multi-session, small group discussion interventions focused on critically 
examining gender and peer norms, IPV and HIV risks, and building communication skills. Third, the GBV/HIV Prevention Intervention (Kalichman et al., 2009), involved a five-session small group discussion approach that drew from Social Cognitive Theory. Male participants in this program were engaged in discussions of gender roles and particularly masculinity and negative attitudes toward women. The program also included skill building related to safer sex practices, relationships, and becoming a more vocal advocate for HIV prevention in the participants' social networks. Fourth, "Partivartan," an adaptation of the intervention Coaching Boys into Men, was implemented in an early adolescent Cricket league in India. This intervention involved role modelling and weekly discussions facilitated by coaches collectively designed to foster gender equitable attitudes, challenge ideas that connect masculinity to dominance, and build skills to recognize and intervene in disrespectful behaviors among peers.

Finally, Real Consent, the only online-based intervention, set in the U.S. for undergraduate men, was also the only one categorized as using solely a one-on-one approach, as the participants did not interact with any other participants in a group or in a community (Salazar et al., 2014). This intervention drew on Social Norms and Social Cognitive Theory as well as bystander-based approaches to support participants in, among other things, critically examining masculine gender roles, and building skills related to respectful sexual negotiation and intervening in situations that could lead to a sexual assault.

Outcomes. Given the wide range of outcomes measured by these programs, we selected a sub-set to review here. These outcomes were chosen to be consistent with both Dworkin and colleagues' 2013 review, and on evidence of empirical links to gender norms and risks for GBV (see for review, Dworkin et al., 2013; Peacock \& Barker, 2014). Included outcomes were: an increase in gender equitable attitudes, a decrease in reported IPV, an increase in care or domestic 
work, and a decrease in social acceptance of IPV. Although the outcome of an increase in care or domestic work may be perceived as more distant to GBV, in the context of gender transformative interventions globally, assessing care or domestic work is a proximal gender equity-related outcome. As noted in the eligibility criteria, all interventions were evaluated through a longitudinal design; length of follow-up ranged from six months (Kalichman et al., 2009; Salazar et al., 2014) to four years (Abramsky et al., 2014).

Out of the eight studies assessing gender equitable attitudes, five showed statistically significant increases (Abramsky et al., 2014; Jewkes et al., 2014; Miller, 2014; Pulerwitz et al., 2015; Salazar et al., 2014), with an additional two demonstrating a trend in this direction (Krishnan et al., 2012; Kyegombe et al., 2014). Three of nine studies tracking IPV documented a statistically significant decrease in reported IPV over time (Jewkes et al., 2014; Pulerwitz et al., 2015; Salazar et al., 2014), although in the study by Jewkes and colleagues, the difference was in IPV reported by women only. Five studies demonstrated a non-statistically significant trend toward reduced rates of IPV (Abramsky et al., 2014; Hossain et al. 2014; Kalichman et al., 2009; Pulerwitz et al., 2015; Wagman et al., 2015). Only two of the studies measured differences in care or domestic work (Hossain et al. 2014; Krishnan et al., 2012), and of these, both showed an increase of men's uptake of these behaviors, with one being statistically significant (Hossain et al., 2014). The outcome of a decrease in social acceptance of gender-based violence was measured by two studies (Abramsky et al., 2014; Krishnan et al., 2012), with Krishnan et al.’s adaptation of Stepping Stones (2012) showing a statistically significant difference reported by both men and women. Lastly, none of the studies documented significant negative results, such as increased IPV, also bolstering the case that gender transformative approaches, on balance, show a trend toward effectiveness. 
Engaging men in violence prevention - 28

\section{Discussion}

The studies included in this review of interventions to engage men to end gender-based violence using a gender transformative approach build on and echo much of the earlier review by Dworkin et al. (2013), and similarly demonstrate promising capacity to affect attitudinal and behavioral change. One of the unique findings of this review was emergence of the gender transformative web-based intervention by Salazar and colleagues (2014). In a field dominated by face to face interventions, the development of an effective and accessible intervention to prevent GBV is noteworthy and requires further examination. Overall, six out of the ten studies demonstrated a statistically significant impact on at least one of the following outcomes; increases in gender equitable attitudes and care or domestic work, and decreases in reported IPV and social acceptance of IPV. Of these the most common impacts were increased gender equitable attitudes and a decrease in reported IPV; this is both a statement about the impact of the programs and of what outcomes were prioritized and measured in these gender transformative interventions. Two outcomes, an increase in care work and the decrease in social acceptance of gender-based violence - that are in keeping with Gupta's gender transformative programming - were not measured by the majority of studies.

A challenge in evaluating programs' adoption and application of a gender transformative framework stems from the varied and sometimes limited conceptualization or available description of what constitutes "gender transformative" programming. Gupta's (2000) speech lays out the conceptual basis for a "gender transformative" approach. However, if the field continues pursuing this as the optimal framework for interventions, the need to more fully operationalize and test key components of "gender transformative" interventions remains. For example, many of the programs included in this review used discussion formats to critically 
evaluate gender norms and ideas about masculinity. Moving forward, there is room for greater specificity around the content and the delivery approach that are most related to the effectiveness of these conversations, as well as of core aspects of desired gender equitable norms that might be relevant across contexts. In a similar vein, interventions captured in this review varied in both the length of sessions and approach used within them (e.g. role modelling vs. small group discussion); teasing out the relative strengths and advantages of these strategies within programs will contribute to more refined knowledge regarding the dosage and approach most associated with changes in outcomes.

Relatedly, the types and combinations of larger intervention components most associated with positive outcomes remains an open question. SASA! was the only intervention in this review using a stand-alone community mobilization format, and it also was the intervention that (measured and) showed a change in three of the four selected outcomes, more than any other intervention. However, positive outcomes were also seen in the one intervention using only a one-on-one modality (Real Consent; Salazar et al., 2014), and among those using mixed formats inclusive of community mobilizing and group-based discussion or education (for example, the South African adaptation of Stepping Stones and Creating Futures; Jewkes et al., 2014). Most programs used multiple components; six used small group formats in combination with other approaches. Further examination of the relative influence of these components could enhance both the theoretical and programmatic foundation of the approach, similar to the nine principles of effective prevention identified by Nation et al. (2003). Further, an expansion of the assessed impacts of gender transformative approaches to outcomes such as participation in social action, and the on-going use of gender equitable behaviors beyond non-violence, could help to place the impact of these promising attitude and behavior change programs in the context of larger 
movements toward social change. Finally, gender transformative approaches can disproportionately focus on the engagement of cisgender men in the context of heterosexual relationships, although they are not intended to be gender exclusive. Future refinement of this approach necessitates a critical evaluation of gender and sexuality inclusivity in the service of full community participation in ending violence.

\section{Domain 3: Men's social action}

The final proposed domain of men's engagement is social action aimed at the eradication of GBV, and more generally, at pursuing gender justice. As we suggest in Figure 1, producing social activists and supporting macro-level social action are situated as both potential outgrowths of many GBV prevention programs that engage men, and also as vehicles or catalysts for "new" men's initial recruitment into gender justice efforts. Although we take up this domain last here, in many ways, men and boys' involvement in anti-GBV efforts began as social action. This history is well-chronicled elsewhere (see for example, Messner et al., 2015; Pease, 2008). In brief, early efforts by men to support and join (largely women's) anti-violence and gender equality movements in the 1970s and 1980s necessitated coalition building, and community organizing and awareness work among men. Over the years, these organizations have included but are in no way limited to the Oakland Men's Project (U.S.), the White Ribbon Campaign (Canada), Men's Action to Stop Violence Against Women (India), Sonke (South Africa), and more recently, regional and international networks of GBV prevention and gender justice organizations such as MenEngage (www.menengage.org). Across these organizations, goals have been articulated broadly through invoking the somewhat conceptually fluid notions of gender justice and gender equality. Here, we use the term "gender justice" within the social action domain to correspond to conceptualizations by UN Women, to connote actions by and on 
behalf of women "to redress disadvantage; to counter stigma, prejudice, humiliation and violence; to transform social and institutional structures; and to facilitate participation, both in the form of political participation and social inclusion" (Fredman \& Goldblatt, 2015, p. 2). The social action domain is also perhaps the most diffuse and multi-faceted arena of men's antiviolence involvement, with boundaries that are somewhat porous in relation to the initial recruitment and attitude/behavior change domains, respectively. As noted above, for example, many gender transformative interventions incorporate larger community mobilization and social action strategies in their efforts, often with twin aims of reaching out to previously unengaged community members and fostering gender-equitable attitudes, behaviors, and norms among individual boys and men within communities.

Scholars and activists have articulated components of a social action agenda to end GBV globally with increasing clarity. For example, Pease (2008) argues that a central role of male anti-violence stakeholders is to engage "political, cultural and religious leaders who are in positions to influence change" (p. 3), most of whom, globally, are men, as well as to advocate for system-level interventions that institutionalize prevention programming and men's responsibility to contribute to GBV prevention. Peacock and Barker (2014) add to this in a reflection on the state of men's anti-violence engagement. They suggest that core elements of broader social action include 1) coalition-building between governmental, private, and regional organizations in ways that formalize and institutionalize funding and support for GBV prevention programming, 2) gender-equitable policy advocacy that is coupled with community organizing and public education campaigns to foster an accurate understanding of the benefits of GBV-related policies and that attempts to minimize backlash, and 3) mechanisms for macro-level accountability in which gender justice organizations publicly contest media, policies, or behavior on the part of 
political, spiritual, and economic leaders that promotes or excuses gender-based violence. Increasingly, regional networks of GBV prevention and men's engagement organizations promote multi-issue social and policy advocacy, inclusive of issues such as sexual and reproductive rights, equity in domestic care-giving practices, and anti-racism and anti-oppression work as inter-related outcomes central to the larger project of gender justice and ending GBV (see for example, menengage.org).

Cataloguing the largely descriptive literature regarding the enormous range of influential social action efforts globally is beyond the scope of this review. We include this domain in our model, however, to place men's anti-violence engagement in the larger context of GBV prevention and gender justice movements. In doing so, we promote two ideas consistent with a gender transformative lens. First, we echo scholars and activists such as Pease (2008) and Peacock and Barker (2014) in arguing that social action - defined here as efforts to address structural, social, and political contributors to GBV - should both inform and subsume any conceptualization of the purpose of men's anti-violence involvement. As Pease (2008) suggests, a focus on engaging men runs the risk of placing disproportionate emphasis on work with individual men, at the potential expense of focusing on larger social change efforts. While an important domain, interventions aimed at individual attitude and behavior change are just one component of comprehensive prevention efforts, which to be effective, must occur at multiple levels of the social ecology (e.g., Nation et al., 2003). Second, we suggest that as a critical and more holistic domain, social action is inclusive of all genders' and communities' efforts, and is therefore the point at which “men's engagement" ceases to be a separate consideration or goal. While men's organizations' contributions to social action efforts are critical, men's participation is not necessarily the end goal or hallmark of success of these efforts. 
Relatedly, we join others such as Jewkes and colleagues (2015) and suggest that men's engagement work in our first two proposed domains should be conceptualized and evaluated in the context of how that work eventually supports and feeds whole communities' social efforts to eradicate GBV and to support gender justice. Effective social action is buttressed by the degree to which individual engaged men carry forward and actively embody support for gender equitable behavior, norms, and policies in their social networks, institutions, and communities. As an emerging field, little evaluation related to men's engagement has yet focused on the degree to which men who have participated in GBV prevention programs view themselves as on-going stakeholders in gender justice efforts, or sustain gender-equitable behaviors in their social contexts over time. Further, it is unclear whether particular initial recruitment strategies (domain 1), or particular components of gender transformative prevention interventions (domain 2), are more likely to support trajectories that include men's participation in on-going GBV prevention or social action efforts. An exception to this was a follow-up study of the Men's Action to Stop Violence Against Women campaign in India (Das et al., 2012), in which men involved in implementing programming were compared with men who were exposed and not exposed to GBV prevention programming, respectively. Consistently, the "activist" men involved in programming reported more progressive, gender-equitable attitudes and perceived norms than the merely "exposed" and control community men, suggesting a lasting impact of anti-violence involvement on men's views of gender and gender justice. Much more work is needed to assess not only what most effectively pulls men into GBV prevention programs and work, but on the longer term impact of programs on men's identity as activists as well as the ways that these programs support and feed into larger gender justice social change efforts.

\section{Limitations}


Limitations to this review include the parameters placed on included literature.

Restricting the review to peer-reviewed literature and literature available in English excludes an enormous volume of relevant documents and the programmatic wisdom they contain. To maintain a workable scope for this paper, we also restricted our review of intervention outcomes to those consistent with the 2013 review by Dworkin et al. and with impacts theorized to be linked specifically with gender transformative approaches to violence prevention. Most of the programs included in our review of interventions aimed at attitude and behavior change, however, assessed their often successful impact on additional outcomes such as bystander behavior and intentions, and reductions in sexual risk. Summarizing all of these findings was simply beyond the space available here. This review also focuses largely on evaluating the programmatic elements and operationalization of gender transformative program principles across domains of men's engagement. Additional work is needed to assess the strengths and limitations of the research methodologies employed across the literature included in this review; these methodologies hold important implications for the extent to which programs' impact on intended outcomes can be understood.

\section{Conclusion}

Incorporating men and boys into the global project of ending gender-based violence has become an increasingly institutionalized component of prevention work. We suggest that viewing men's engagement as an inter-related continuum of domains allows for a more precise conceptualization of factors related to the successful and ethical engagement of men over time, as well as for placing men's anti-violence participation in the larger and perhaps more important context of community and social action aimed at ending violence. Additionally, in accordance with the successful implementation of gender transformative approaches in other gender-related 
social issues such as HIV prevention (Dworkin et al. 2013), we echo others in suggesting that programming and community mobilization endeavors that work through a gender transformative lens offer particular promise for promoting violence-preventative change. Capitalizing on both the model offered here and the promise of gender transformative approaches will require continued conceptual development of gender transformative frameworks, and the particular interventive strategies that most effectively achieve true attitudinal, behavioral, and social change. In particular, work is needed to evaluate how gender transformative strategies can be leveraged for the initial recruitment and engagement of men in ways that sustain their involvement as anti-violence stakeholders. Given the leadership of the global South in developing and implementing gender transformative strategies, particularly by countries in Africa, South Asia, and South America, cross-regional learning and fertilization may be critical to bolstering the successful conceptualization and uptake of gender transformative-informed prevention, in service of the broader goals of global gender justice. 


\section{References}

Abramsky, T., Devries, K., Kiss, L., Nakuti, J., Kyegombe, N., Starmann, E., ... \& Watts, C. (2014). Findings from the SASA! Study: a cluster randomized controlled trial to assess the impact of a community mobilization intervention to prevent violence against women and reduce HIV risk in Kampala, Uganda. BMC medicine, 12(1), 122.

*Alcalde, M. C. (2014). An intersectional approach to Latino anti-violence engagement. Culture, Society, and Masculinities, 6, 35-51.

Allen, C. T. (2010). Engaging men in violence prevention: Empirically examining theoretical barriers and catalysts. Unpublished Doctoral Dissertation.

Barker, G., Ricardo, C. \& Nascimento, M. (2007). Engaging men and boys in changing genderbased inequity in health: Evidence from programme interventions. World Health Organization: Geneva.

Black, M.C., Basile, K.C., Breiding, M.J., Smith, S.G., Walters, M.L., Merrick, M.T., et al. (2011). The National Intimate Partner and Sexual Violence Survey (NISVS): 2010 Summary Report. Atlanta, GA: NCIPC, CDC

*Carlson, J., Casey, E.A., Edleson, J., Tolman, R., Neugut, T., \& Kimball, E. (2015). Strategies to engage men and boys in violence prevention: A global organizational perspective. Violence Against Women, 21, 1406-1425.

*Casey, E.A. (2010) Strategies for engaging men as anti-violence allies: Implications for ally movements. Advances in Social Work, 11, 267-282.

*Casey, E.A., \& Smith, T. (2010). “How can I not?”: Men's pathways to involvement in antiviolence against women work. Violence Against Women, 16, 953-973. 
*Casey, E.A., Tolman, R. M., Carlson, J., Allen, C. T., \& Storer, H. L. (2016; online first). What motivates men's involvement in gender-based violence prevention? Latent class profiles and correlates in an international sample of men. Men and Masculinities.

*Coulter, R. P. (2003). Boys doing good: Young men and gender equity. Educational Review, $55,135-145$.

Das, A., Mogford, E., Singh, S. K., Barbhuiya, R. A., Chandra, S., \& Wahl, R. (2012). Reviewing responsibilities and renewing relationships: An intervention with men on violence against women in India. Culture, Health and Society, 14, 659-675.

Dworkin, S.L., Colvin, C., Hatcher, A., \& Peacock, D. (2012). Men’ perceptions of women's rights and changing gender relations in South Africa: Lessons for working with men and boys in HIV and antiviolence programs. Gender and Society, 26, 97-120

Dworkin, S.L., Flemming, P.J., \& Colvin, C. J. (2015). The promises and limitations of gendertransformative health programming with men: Critical reflections from the field. Culture, Health and Society, 17, S128-S143.

Dworkin, S. L., Treves-Kagan, S., Lippman, S.A. (2013). Gender-transformative interventions to reduce HIV risks and violence with heterosexually-active men: A review of the global evidence. AIDS and Behavior, 17, 2845-2863.

*Falb, K. L., Annan, J., King, E., Hopkins, J., Kpebo, D., \& Gupta, J. (2014). Gender norms, poverty and armed conflict in Côte D'Ivoire: Engaging men in women's social and economic empowerment programming. Health Education Research, 29(6), 1015-1027.

Fleming, P. J., Lee, J. G. L., \& Dworkin, S. L. (2014). “Real men don't”: Constructions of masculinity and inadvertent harm in public health interventions. American Journal of Public Health, 104, 1029-1035. 
Flood, M. \& Pease, B. (2009). Factors influencing attitudes to violence against women. Trauma, Violence and Abuse, 10, 125-142.

Fredman, S. \& Goldblatt B. (2015). Discussion paper: Gender equality and human rights. UN Women, New York

Gupta, G. R. (2000). Gender, sexuality, and HIV/AIDS: The what, the why, and the how. Can HIV AIDS Policy Law Rev, 5(4), 86-93.

*Gurman, T.A., Trappler, R.M., Acosta, A., McCray, P.A., Cooper, C.M., \& Goodsmith, L. (2014).'By seeing with our own eyes, it can remain in our mind:' Qualitative evaluation findings suggest the ability of participatory video to reduce gender-based violence in conflict-affected settings. Health Education Research, 29, 690-701.

Hossain, M., Zimmerman, C., Kiss, L., Abramsky, T., Kone, D., Bakayoko-Topolska, M., \& ... Watts, C. (2014). Working with men to prevent intimate partner violence in a conflictaffected setting: a pilot cluster randomized controlled trial in rural Côte d'Ivoire. $B M C$ Public Health, 14(1), 1-28. doi:10.1186/1471-2458-14-339

Jewkes, R., Gibbs, A., Jama-Shai, N., Willan, S., Misselhorn, A., Mushinga, M., \& ... Skiweyiya, Y. (2014). Stepping Stones and Creating Futures Intervention: Shortened interrupted time series evaluation of a behavioural and structural health promotion and violence prevention intervention for young people in informal settlements in Durban, South Africa. BMC Public Health, 14(1), 1-19. doi:10.1186/1471-2458-14-1325

Jewkes, R., Flood, M., \& Lang. J. (2015). From work with men and boys to changes of social norms and reductions of inequities in gender relations: A conceptual shift in prevention of violence against women and girls. Lancet, 385, 1580-1589. 
*Kalichman, S.C., Simbayi, L.C., Cloete, A., Cherry, C., Strebel, A., Kalichman, M.O.,... \& Cain, D. (2008). HIV/AIDS Risk reduction and domestic violence prevention intervention for South African Men. International Journal of Men's Health, 7, 255-273.

Kalichman, S. C., Simbayi, L. C., Cloete, A., Clayford, M., Arnolds, W., Mxoli, M., ... \& Kalichman, M. O. (2009). Integrated gender-based violence and HIV risk reduction intervention for South African men: results of a quasi-experimental field trial. Prevention Science, 10(3), 260-269. doi: 10.1007/s11121-009-0129-х

Katz, J. (1995). Reconstructing masculinity in the locker room: The mentors in violence prevention project. Harvard Educational Review, 65, 163-175.

Kaufman, M., Barker, G., Peacock, D., Vess, J., Robles, O., Sharafi, L., \& MenEngage Steering Committee. (2014). Engaging Men, Changing Gender Norms: Directions for GenderTransformative Action. MenEngage-UNFPA Advocacy Brief. Retrieved from http://www.unfpa.org/sites/default/files/resource-pdf/Advocacy\%20Brief\%20Gender\%20Norms-1.pdf

Krishnan, S., Vohra, D., deWalque, D., Medlin, C., Nathan, R. \& Dow, W. H. (2012; epub). Tanzanian couples' perspectives of gender equity, relationship power, and intimate partner violence: Findings from the RESPECT study. AIDS Research and Treatment, http://dx.doi.org/10.1155/2012/187890

Kyegombe, N., Abramsky, T., Devries, K.M., Starmann, E., Michau, L., Nakuti, J., ... Watts, C., (2014). The impact of SASA! a community mobilization intervention, on reported HIVrelated risk behaviors and relationship dynamics in Kampala, Uganda. Journal of the International AIDS Society, 17. doi: 10.7448/IAS.17.1.19232 
Masters, N. T. (2010). "My strength is not for hurting": Men's anti-rape websites and their construction of masculinity and male sexuality. Sexualities, 13, 33-46.

McMahon, S. \& Dick, A. (2011). Being in a room with like-minded men: An exploratory study of men's participation in a bystander intervention program to prevent intimate partner violence. Journal of Men's Studies, 19, 3-18.

*Messner, M.A., Greenberg, M.A., \& Peretz, T. (2015). Some men: Feminist allies and the movement to end violence against women. New York: Oxford University Press

Miller, E., Das, M., Tancredi, D.J., McCauley, H.L., Virata, M.C.D., Nettiksimmons, J... \& Verma, R. (2014). Evaluation of a gender-based violence prevention program for student athletes in Mumbai, India. Journal of Interpersonal Violence, 29, 758-778.

Nation, M., Crusto, C., Wandersman, A., Kumpfer, K. L., Seybolt, D., Morrissey-Kane, E., \& Davino, K. (2003). What works in prevention: Principles of effective prevention programs. American Psychologist, 58(6-7), 449.

*Nelson, A., Lewy, R., Ricardo, F., Dovydaitis, T., Hunter, A... Kugel, C. (2010). Eliciting behavior change in a US sexual violence and IPV prevention program through utilization of Freire and discussion facilitation. Health Promotion International, 25, 299-308.

Peacock, D., \& Barker, G. (2014). Working with Men and Boys to Prevent Gender-based Violence Principles, Lessons Learned, and Ways Forward. Men and Masculinities, 17(5), 578-599.

Pease, B. (2008). Engaging men in men's violence prevention: Exploring the tensions, dilemmas and possibilities. Australian Domestic \& Family Violence Clearinghouse. 
*Piccigallo, J.R., Lilley, T.G. \& Miller, S.L. (2012). "It's cool to care about sexual violence:" Men's experiences with sexual assault prevention, Men and Masculinities, 15, 507-525. Doi: $10.1177 / 1097184 X 12458590$

Pulerwitz, J., Hughes, L., Mehta, M., Kidanu, A., Verani, F., \& Tewolde, S. (2015). Changing gender norms and reducing intimate partner violence: results from a quasi-experimental intervention study with young men in Ethiopia. American Journal of Public Health, 105(1), 132-137. doi:10.2105/AJPH.2014.302214

Ratele, K. (2014). Gender equity in the abstract and practice. Men and Masculinities, 17, 510514.

Rich, M.D., Utley, E.A., Janke, K., \& Moldoveanu, M. (2010). “I’d Rather Be Doing Something Else:" Male Resistance to Rape Prevention Programs. Journal of Men's Studies, 18, 268288.

Salazar, L. F., Vivolo-Kantor, A., Hardin, J., \& Berkowitz, A. (2014). A web-based sexual violence bystander intervention for male college students: randomized controlled trial. Journal of Medical Internet research, 16(9), e203. doi: 10.2196/jmir.3426

Santana, M. C., Raj, A., Decker, M. R., La Marche, A., \& Silverman, J. G. (2006). Masculine gender roles associated with increased sexual risk and intimate partner violence perpetration among young adult men. Journal of Urban Health, 83(4), 575-585.

*Torres, V. M. S., Goicolea, I., Edin, K., \& Öhman, A.(2012; epub). "Expanding your mind:” The process of constructing gender-equitable masculinities in young Nicaraguan men participating in reproductive health or gender training programs. Global Health Action, 5 UNFPA \& Promundo. (2010). Engaging men and boys in gender equality and health: A global toolkit for action. Retrieved from http://www.unfpa.org/public/home/publications/ 
pid/6815

Wagman, J.A., Gray, R.H., Campbell, J.C., Thoma, M., Ndyanabo, A., Ssekasanvu, J., ... Brahmbhatt, H. (2015). Effectiveness of an integrated intimate partner violence and HIV prevention intervention in Rakai, Uganda: Analysis of an intervention in an existing cluster randomised cohort. Lancet Global Health, 3, e23-e33. doi: 10.1016/S214-109X(14)7034-4 


\section{Table 1. Key Findings - implications for research and practice}

\section{As the knowledge base on engaging men in GBV prevention matures, it is useful to conceptualize men's engagement as a process with three inter-related domains, each with some unique considerations; 1) initial recruitment and outreach 2) supporting violence preventative attitude and behavior change, and 3) participation in social action (see Figure 1).}

2. Previous literature and the results from this review suggest that GBV prevention programs informed by a gender transformative approach hold considerable promise for promoting violence preventative attitudes and behaviors among men.

\section{Given emerging evidence of the efficacy of gender transformative approaches for intervention} design, we suggest that the conceptualization and evaluation of the domains of initial outreach and engagement of men, as well as their participation in social action, can be enhanced through the application of a gender transformative lens.

4. As gender transformative approaches to prevention increase and mature, research is needed to distill the most effective gender-related content and interventive components within the gender transformative umbrella.

5. Across domains of men's engagement in GBV prevention, tailoring programming to local context and culture in ways that account for men's various social positions, is likely to contribute to effectiveness. At the same time, similarities in outreach and intervention strategies can be seen across regions, highlighting the importance of cross-region information sharing and collaboration.

6. Although the participation of male-identified individuals in GBV prevention is a crucial aspect of work to end violence, the engagement of men and boys should be evaluated in the context of overall efforts to end GBV, not as an end unto itself. 
Figure 1. Domains of men's engagement in gender-based violence prevention: A conceptual model

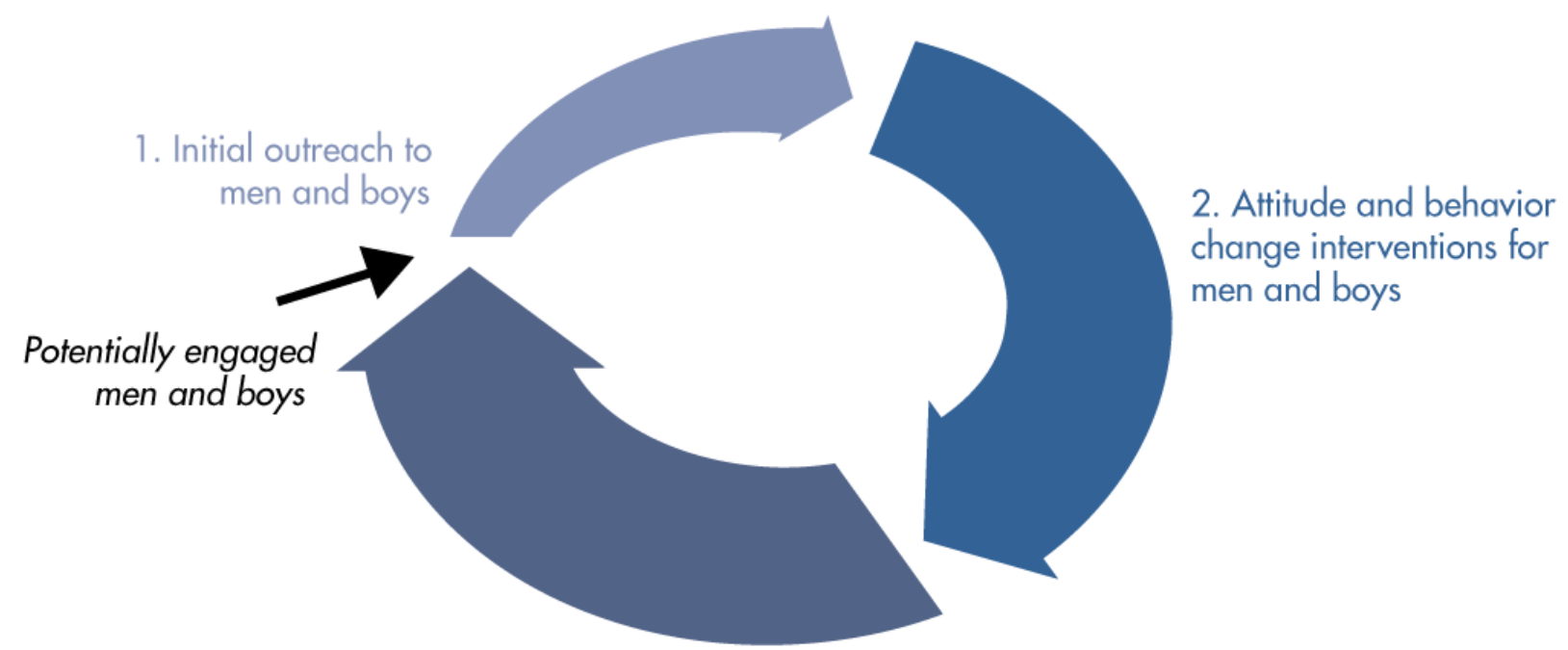

3. Ongoing social action 


\section{Table 2. Summary of Intervention Components and Outcomes}

\begin{tabular}{|c|c|c|c|c|c|c|c|c|}
\hline Intervention/Source & Participants & $\begin{array}{l}\text { Geographic } \\
\text { Location }\end{array}$ & Intervention approach & $\begin{array}{l}\text { Intervention } \\
\text { Components }\end{array}$ & $\begin{array}{l}\text { Increase } \\
\text { "gender- } \\
\text { equitable } \\
\text { attitudes" }\end{array}$ & $\begin{array}{l}\text { Decrease } \\
\text { in } \\
\text { reported } \\
\text { IPV }\end{array}$ & $\begin{array}{l}\text { Increase in } \\
\text { Care or } \\
\text { domestic } \\
\text { work }\end{array}$ & $\begin{array}{l}\text { Decrease in } \\
\text { social } \\
\text { acceptance } \\
\text { of IPV }\end{array}$ \\
\hline $\begin{array}{l}\text { 1. SASA! } \\
\text { (Abramsky et al., 2014) }\end{array}$ & $18-49$ year old $M$ and $W$ & $\begin{array}{l}\text { Kampala } \\
\text { Uganda }\end{array}$ & $\begin{array}{l}\text { Community mobilization intervention, training } \\
\text { community activists, community } \\
\text { conversations, films, poster presentations, and } \\
\text { meetings. } 2.8 \text { years }\end{array}$ & $\mathrm{CM}$ & $\begin{array}{l}\mathrm{Y}^{*}(\text { both } \mathrm{M} \\
\text { and } \mathrm{W})\end{array}$ & $\begin{array}{l}\text { Phy } Y \\
\text { Sex } Y\end{array}$ & N/A & $\begin{array}{l}\mathrm{Y}^{*}(\text { both } \mathrm{M} \\
\text { and } \mathrm{W})\end{array}$ \\
\hline $\begin{array}{l}\text { 2. Men \& Women in } \\
\text { Partnership Initiative } \\
\text { (Hossain et al., 2014) }\end{array}$ & $\begin{array}{l}12 \text { pair-matched } \\
\text { communities } M \text { and } W\end{array}$ & $\begin{array}{l}\text { Cote } \\
\text { d'Ivoire }\end{array}$ & $\begin{array}{l}\text { 16-week IPV intervention: men's discussion } \\
\text { group } \\
\text { Community-based awareness raising }\end{array}$ & SG & $\begin{array}{l}\text { N/A } \\
\text { (WRFS - Y }\end{array}$ & Y & $\mathrm{Y}^{*}$ & $\mathrm{~N} / \mathrm{A}$ \\
\hline $\begin{array}{l}\text { 3. Stepping Stones and } \\
\text { Creating Futures } \\
\text { (Jewkes et al., 2014) }\end{array}$ & $18-30$ year old $M$ and $W$ & $\begin{array}{l}\text { South } \\
\text { Africa }\end{array}$ & $\begin{array}{l}\text { Facilitated group intervention, } 11 \text { 3-hour group } \\
\text { sessions in single sex. Participatory learning } \\
\text { approaches - HIV and violence prevention }\end{array}$ & SG & $\begin{array}{l}Y^{*} M ; Y \\
W \text { mixed }\end{array}$ & $\begin{array}{l}\text { Sex } Y^{*} W \\
\text { N M }\end{array}$ & $\mathrm{N} / \mathrm{A}$ & $\mathrm{N} / \mathrm{A}$ \\
\hline $\begin{array}{l}\text { 4. GBV/HIV vs. Alcohol/HIV } \\
\text { (Kalichman et al., 2009) }\end{array}$ & Xhosa M mean age 30.2 & $\begin{array}{l}\text { Cape Town, } \\
\text { South } \\
\text { Africa }\end{array}$ & $\begin{array}{l}\text { 5-sessions Examine personal and community } \\
\text { consequences of GBV and HIV/AIDS. Used skill } \\
\text { building and personal goal setting. }\end{array}$ & SG & N/A & $\mathrm{Y}$ & $\mathrm{N} / \mathrm{A}$ & $\mathrm{N} / \mathrm{A}$ \\
\hline $\begin{array}{l}\text { 5. RESPECT } \\
\text { (Krishnan et al., 2012) }\end{array}$ & $\begin{array}{l}18-30 \text { year old } M \text { and } W, \\
10 \text { villages }\end{array}$ & Tanzania & $\begin{array}{l}\text { Conditional cash transfers, STI, HIV counseling } \\
\text { and testing, group counseling based on } \\
\text { Stepping Stones. }\end{array}$ & SG, ONO & $\begin{array}{l}\mathrm{Y}(\mathrm{M} \text { and } \\
\mathrm{W})\end{array}$ & $\mathrm{Y}(\mathrm{W})$ & $\mathrm{N} / \mathrm{A}$ & $\begin{array}{l}Y(M \text { and } \\
W)\end{array}$ \\
\hline $\begin{array}{l}\text { 6. SASA! } \\
\text { (Kyegombe, et al., 2014) }\end{array}$ & $18-49$ year old $M$ and $W$ & $\begin{array}{l}\text { Kampala } \\
\text { Uganda }\end{array}$ & Community mobilization intervention 2.8 years & $\mathrm{CM}$ & $\begin{array}{l}\mathrm{Y}(\mathrm{M} \text { and } \\
\mathrm{W})\end{array}$ & N/A & $\mathrm{Y}(\mathrm{M})$ & $\mathrm{N} / \mathrm{A}$ \\
\hline $\begin{array}{l}\text { 7. Parivartan - Adaptation of } \\
\text { Coaching Boys Into Men } \\
\text { (Miller et al., 2014) }\end{array}$ & $\begin{array}{l}10-16 \text { year old male } \\
\text { cricket players from } 46 \\
\text { schools }\end{array}$ & $\begin{array}{l}\text { Mumbai, } \\
\text { India }\end{array}$ & Coaches lead 45-60 min weekly discussions & SG & $Y^{*}$ & $\mathrm{~N}$ & $\mathrm{~N} / \mathrm{A}$ & $\mathrm{N} / \mathrm{A}$ \\
\hline $\begin{array}{l}\text { 8. Male Norms Initiative } \\
\text { (Pulerwitz et al., 2015) }\end{array}$ & $15-24$ year old $M$ & $\begin{array}{l}\text { Addis } \\
\text { Ababa, } \\
\text { Ethiopia }\end{array}$ & $\begin{array}{l}\text { Group education (GE): } 8 \text { Sessions } 2 \text { or } 3 \mathrm{~h} \\
\text { facilitated by } 2 \text { or } 3 \text { peer educators. } \\
\text { Community engagement (CE) }\end{array}$ & SG, CM & $Y^{*}(G E+C E)$ & $\begin{array}{l}\mathrm{Y}^{*} \text { both } \\
\text { interventi } \\
\text { ons }\end{array}$ & $\mathrm{N} / \mathrm{A}$ & $\mathrm{N} / \mathrm{A}$ \\
\hline $\begin{array}{l}\text { 9. Real Consent } \\
\text { (Salazar et al., 2014) }\end{array}$ & $\begin{array}{l}\text { 18-24 year old, } \\
\text { Undergrad hetero/bi M }\end{array}$ & $\begin{array}{l}\text { California, } \\
\text { USA }\end{array}$ & $\begin{array}{l}\text { Six } 30 \text {-minute media-based and interactive } \\
\text { modules }\end{array}$ & ONO & $\mathrm{Y}^{*}$ & $\mathrm{Y}^{*}$ & $\mathrm{~N} / \mathrm{A}$ & $\mathrm{N} / \mathrm{A}$ \\
\hline $\begin{array}{l}\text { 10. The Safe Homes and } \\
\text { Respect for Everyone } \\
\text { Project (Wagman et } \\
\text { al.,2015) }\end{array}$ & 15-49 year old $M$ and $W$ & $\begin{array}{l}\text { Rakai, } \\
\text { Uganda }\end{array}$ & $\begin{array}{l}\text { Community mobilization and screening and } \\
\text { brief intervention. }\end{array}$ & $\begin{array}{l}\text { SG, CM, } \\
\text { ONO }\end{array}$ & N/A & $\begin{array}{l}Y(M, P) \\
Y-\text { Mixed } \\
(W \\
\text { reported })\end{array}$ & $\mathrm{N} / \mathrm{A}$ & $\mathrm{N} / \mathrm{A}$ \\
\hline
\end{tabular}

Note: $M=$ men; $W=$ women; $N C=$ No control; $S G=$ small groups; $C M=$ community mobilization; $O N O=$ one on one; *=statistically significant; $P=$ perpetration; $Y=y e s ; N=$ no; $N A=$ not applicable 